\title{
The broad-spectrum anti-DNA virus agent cidofovir inhibits lung metastasis of virus-independent, FGF2-driven tumors
}

\author{
Sandra Liekens ${ }^{1}$, Sam Noppen ${ }^{1}$, Sofie Gijsbers ${ }^{1}$, Rebecca Sienaert ${ }^{1}$, Roberto \\ Ronca ${ }^{2}$, Chiara Tobia ${ }^{2}$ and Marco Presta ${ }^{2}$ \\ ${ }^{1}$ KU Leuven, Rega Institute for Medical Research, Leuven, Belgium \\ 2 Department of Molecular and Translational Medicine, University of Brescia, Brescia, Italy \\ Correspondence to: Sandra Liekens, email: sandra.liekens@rega.kuleuven.be
}

Keywords: basic fibroblast growth factor, melanoma, metastasis, nucleoside phosphonate, survival

Received: November 18,2014 Accepted: December 26, $2014 \quad$ Published: December 31, 2014

This is an open-access article distributed under the terms of the Creative Commons Attribution License, which permits unrestricted use, distribution, and reproduction in any medium, provided the original author and source are credited.

\section{ABSTRACT}

The FDA-approved anti-DNA virus agent cidofovir (CDV) is being evaluated in phase II/III clinical trials for the treatment of human papillomavirus (HPV)-associated tumors. However, previous observations had shown that CDV also inhibits the growth of vascular tumors induced by fibroblast growth factor-2 (FGF2)-transformed FGF2-TMAE cells. Here, we demonstrate that CDV inhibits metastasis induced by FGF2-driven, virus-independent tumor cells. Pre-treatment of luciferase-expressing FGF2-T-MAE cells with CDV reduced single cell survival and anchorage-independent growth in vitro and lung metastasis formation upon intravenous inoculation into SCID mice. This occurred in the absence of any effect on homing of FGF2-T-MAE cells to the lungs and on the growth of subconfluent cell cultures or subcutaneous tumors in mice. Accordingly, CDV protected against lung metastasis when given systemically after tumor cell injection. Lung metastases in CDV-treated mice showed reduced Ki67 expression and increased nuclear accumulation of p53, indicating that CDV inhibits metastasis by affecting single cell survival properties. The anti-metastatic potential of CDV was confirmed on B16-F10 melanoma cells, both in zebrafish embryos and mice. These findings suggest that CDV may have therapeutic potential as an anti-metastatic agent and warrants further study to select those tumor types that are most likely to benefit from CDV therapy.

\section{INTRODUCTION}

The nucleotide analogue cidofovir $[(S)-1-(3-$ hydroxy-2-phosphonyl-methoxypropyl)cytosine, CDV] is a broad-spectrum antiviral agent approved (Vistide ${ }^{\circledR}$ ) for the treatment of cytomegalovirus-induced retinitis in AIDS patients [1,2].

Besides its antiviral activity, CDV possesses potent anti-tumor activity in various experimental models of virus-associated tumors [3-8]. In vitro, CDV inhibits the proliferation of HPV-positive (HPV+) cervical carcinoma cells by accumulation of cells in the S-phase, induction of apoptosis and stimulation of the tumor suppressor proteins p53 and pRb [8,9]. Moreover, a synergistic effect of CDV and radiation was observed in HPV18+ cervical carcinoma cells [10] and in head and neck squamous cell carcinoma cells [11]. This effect was attributed, at least in part, to inhibition of angiogenesis mediated by p53-dependent reduction in vascular endothelial growth factor (VEGF) expression [10].

In keeping with these observations, CDV proved active in patients with recurrent Epstein-Barr virusinduced nasopharyngeal carcinoma (NPC) and is increasingly being used off-label to treat a variety of human papillomavirus (HPV)-induced premalignant and malignant lesions [12-15]. In fact, intralesional CVD has been one of the mainstays of adjuvant therapy in patients with recurrent respiratory papillomatosis (RRP) since 1998 [16]. Moreover, CDV has recently been evaluated in phase II clinical trials for HPV-associated high grade 
cervical and vulvar carcinoma and showed promise for topical treatment of cervical intraepithelial neoplasia grade (CIN) 2+ lesions [17].

Besides its virus-related antineoplastic activity, increasing evidence indicates that CDV may show therapeutic efficacy in cancer beyond the setting of viral infection. Indeed, CDV inhibits intracranial glioblastoma growth by promoting DNA double-strand breaks and apoptosis following its incorporation into the DNA [18]. Also, CDV proved effective in the treatment of patients with basal cell carcinoma [19] and cutaneous squamous cell carcinoma [20].

Fibroblast growth factor-2 (FGF2) was one of the first angiogenic factors to be described [21]. Over the years the FGF2/FGF receptor (FGFR) system has been shown to play a major role in angiogenesis, inflammation and in the development and progression of angiogenic diseases and cancer [22-24]. Moreover, accumulating evidence indicates that FGF2 is involved in resistance of tumor vascularization against VEGF inhibitor treatment. Therefore, FGF2 and FGFRs have gained interest as promising targets for drug development in cancer therapy $[25,26]$. In this setting, we generated a stable oncogenic FGF2-overexpressing endothelial (FGF2-T-MAE) cell line able to induce highly vascularized tumors that histologically resemble Kaposi's sarcoma when grafted in immunocompromised mice $[4,27,28]$. Thus, FGF2-TMAE cells represent an interesting model of FGF2-driven tumor development and for assessing the efficacy of antiFGF2 therapeutic approaches. Notably, CDV inhibits the growth of primary tumors induced by FGF2-T-MAE cells that do not express viral oncogenes. The cytostatic and pro-apoptotic activity of CDV in these cells was found to be mediated by increased p53 protein levels and inhibition of FGF2 expression [29]. Relevant to this point, CDV also inhibits the in vivo growth of murine B16 melanoma cells [30], a FGF2-dependent tumor cell line [26 and references therein]. Accordingly, intralesional injection of CDV has been shown to cause the regression of a cutaneous metastasis in a melanoma patient [31].

Metastasis remains the primary cause of mortality in cancer patients. This is mainly due to the fact that micrometastases largely remain unidentified. Thus, the identification and characterization of compounds able to prevent the development of micrometastases and/ or metastatic colonization, remains a challenge [32,33]. Previous observations had shown that CDV exerts an antimetastatic activity in one experimental model involving $\mathrm{HPV}+$ cells [34]. In the present study, we show that CDV inhibits the metastatic growth of virus-independent, FGF2-driven FGF2-T-MAE and melanoma B16 tumors. Evidence is provided that this is associated with the inhibition of single cell survival properties of tumor cells.

\section{RESULTS}

\section{CDV reduces single cell survival of F2T-luc2.9 cells}

We previously showed that the cytostatic activity of CDV in FGF2-T-MAE cells increases with decreasing seeding density [29]. Therefore, we assessed whether CDV affects the capacity of luciferase-expressing FGF2$T$-MAE cells (F2T-luc2.9 cells) to survive as single cells.

We first examined toxicity in subconfluent F2Tluc2.9 cell cultures. Cells were incubated with various concentrations of CDV for $24 \mathrm{~h}$, washed and grown in fresh medium without compound for 5 days. Cell viability was determined at different time points. As previously shown for HPV+ cells (and due to the long half-life of CDV), cytotoxicity of CDV increased with time, in particular from 1 to 3 days after CDV treatment (Fig. 1A), resulting in $\mathrm{CC}_{50}$ values (concentration that reduces the number of living cells by $50 \%$ ) that decreased from $>100$ $\mu \mathrm{g} / \mathrm{ml} 24 \mathrm{~h}$ after CDV treatment to 71,49 and $45 \mu \mathrm{g} / \mathrm{ml}$ after 2, 3 and 6 days, respectively (Fig. 1B).

Next, F2T-luc2.9 cells, pretreated for $24 \mathrm{~h}$ with different concentrations of CDV, were seeded as single cells in the absence of CDV. Colony formation was evaluated after 7 days. CDV significantly inhibited single cell survival and growth (Fig. 1C) at concentrations that did not inhibit subconfluent cultures, as reflected by the reduced number of colonies and smaller colony size (Fig. 1D) of cells pretreated with 10 or $20 \mu \mathrm{g} / \mathrm{ml} \mathrm{CDV}$. At $50 \mu \mathrm{g} / \mathrm{ml}$, no colonies could be detected, whereas this concentration still allowed 50\% survival in subconfluent cultures (Fig. 1A). Additionally, we determined the effect of CDV on detachment-free survival of F2T-luc2.9 cells seeded on agarose. Again, CDV pretreatment (at 10 and $20 \mu \mathrm{g} / \mathrm{ml}$ ) dose-dependently inhibited the clonogenic capacity of the cells (Fig. 1C). These data suggest that CDV may affect the survival of single cells in the blood (in suspension) or after extravasation in the target organ.

\section{CDV pretreatment inhibits lung metastasis of F2T-luc2.9 cells without affecting primary tumor growth}

Prompted by these results we investigated whether CDV inhibits the metastatic potential of F2T-luc2.9 cells after intravenous injection in SCID mice. This experimental metastasis model recapitulates all postintravasation steps of tumor cell metastasis [35].

F2T luc2.9 cells were retained in the lungs within $1 \mathrm{~h}$ after inoculation into the tail vein (Fig. 2A). The luminescent signal, reflecting the amount of living tumor cells in the lungs, progressively declined during the next days, leaving a small number of viable cells that remained 
dormant for approximately 3 weeks. Next, disease progression occurred, as indicated by the exponential increase in luminescent signal in the lungs.

In order to evaluate the anti-metastatic properties of CDV, F2T-luc2.9 cells were pretreated with $10 \mu \mathrm{g} /$ $\mathrm{ml}$ of $\mathrm{CDV}$ for $24 \mathrm{~h}$, i.e. the lowest concentration that inhibited single cell survival in vitro (Fig. 1C). Consistent with the in vitro data, CDV pretreatment resulted in a significant reduction in tumor cell survival in the lungs compared with control cells. Indeed, the luminescent signal decreased 8-fold from day 0 to day 5 after injection for control cells versus 16-fold for CDV-treated cells
(Fig. 2A). Moreover, outgrowth of the surviving cells into macrometastases proceeded more slowly for CDV-treated cells, the luminescent signal increasing more than 100fold from day 19 to 36 for control cells versus 13-fold for CDV-treated cells. This resulted in a significantly reduced weight of harvested lungs at the end of the experiment (Fig. 2C).

CDV was previously shown to inhibit the homing of HPV+ cells to the lungs by inhibition of CXCR4 expression and signaling [34]. However, one hour after cell inoculation equal numbers of luciferase-expressing tumor cells were observed in the lungs of control and

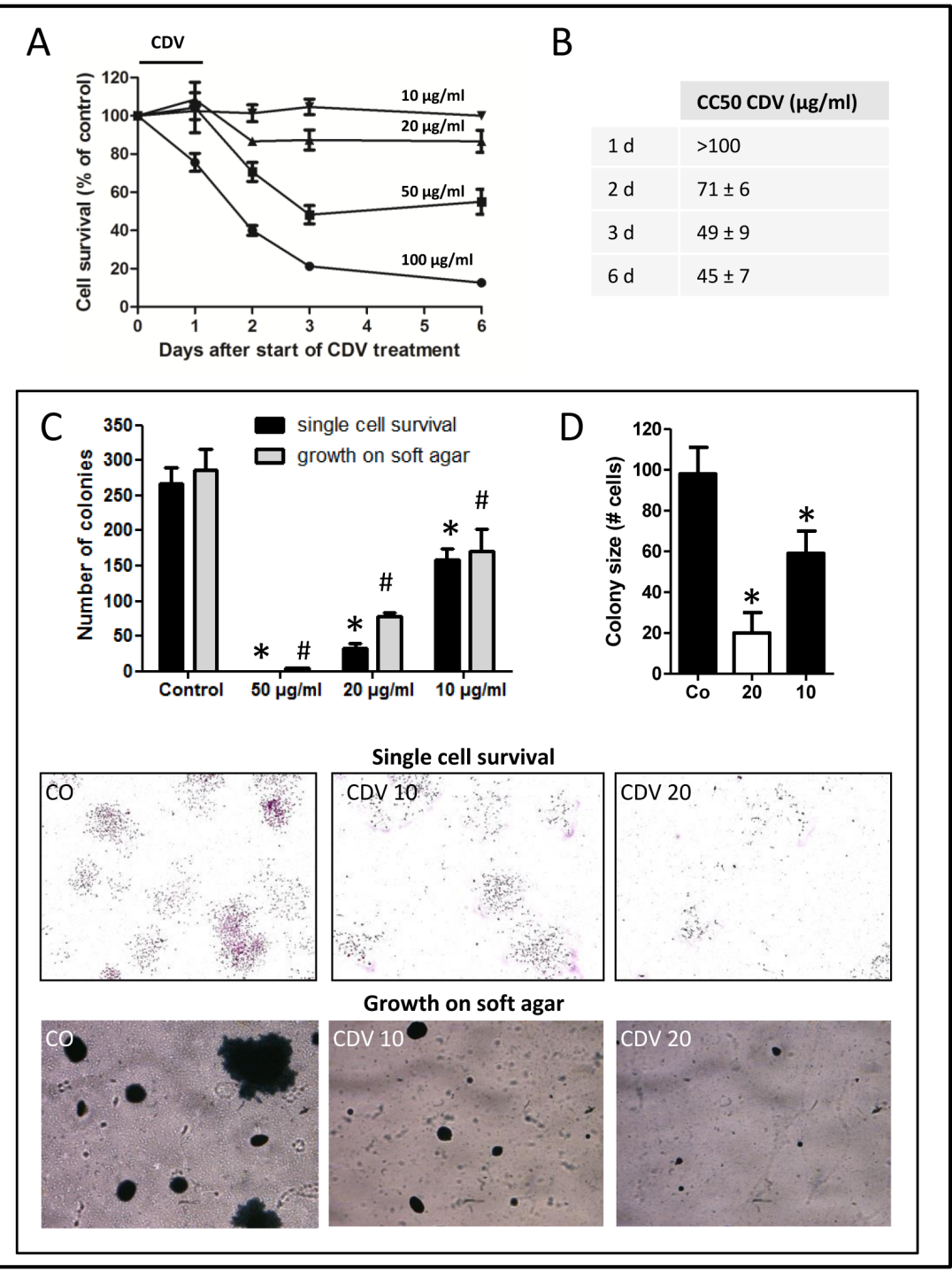

Figure 1: CDV inhibits single cell survival and anchorage-independent growth of F2T-luc2.9 cells. F2T-luc2.9 cells were seeded at 10,000 cells $/ \mathrm{cm}^{2}$. After overnight incubation, the cells were treated with different concentrations of CDV for $24 \mathrm{~h}$. A, B, Cells were washed and incubated in fresh medium without CDV. Cell survival was measured at multiple time points by MTS assay (A) and $\mathrm{CC}_{50}$ values (concentration that reduces cell number by 50\%) were determined (B). C, D, For single cell survival 300 pretreated cells were seeded in 6-well plates in the absence of CDV. After 7 days, the number of colonies (C) and the cells in each colony (D) were determined. ${ }^{*} p<0.05$; Student- $t$-test. For anchorage-independent growth 50,000 pretreated cells were seeded on soft agar in the absence of CDV. After 14 days, the colonies were counted (C). \#p $<0.05$; Student-t-test. Representative pictures of cell colonies on culture dish (upper panel) and agar (bottom panel) are shown. Values are expressed as mean \pm S.E.M. of 3 independent experiments in duplicate. 


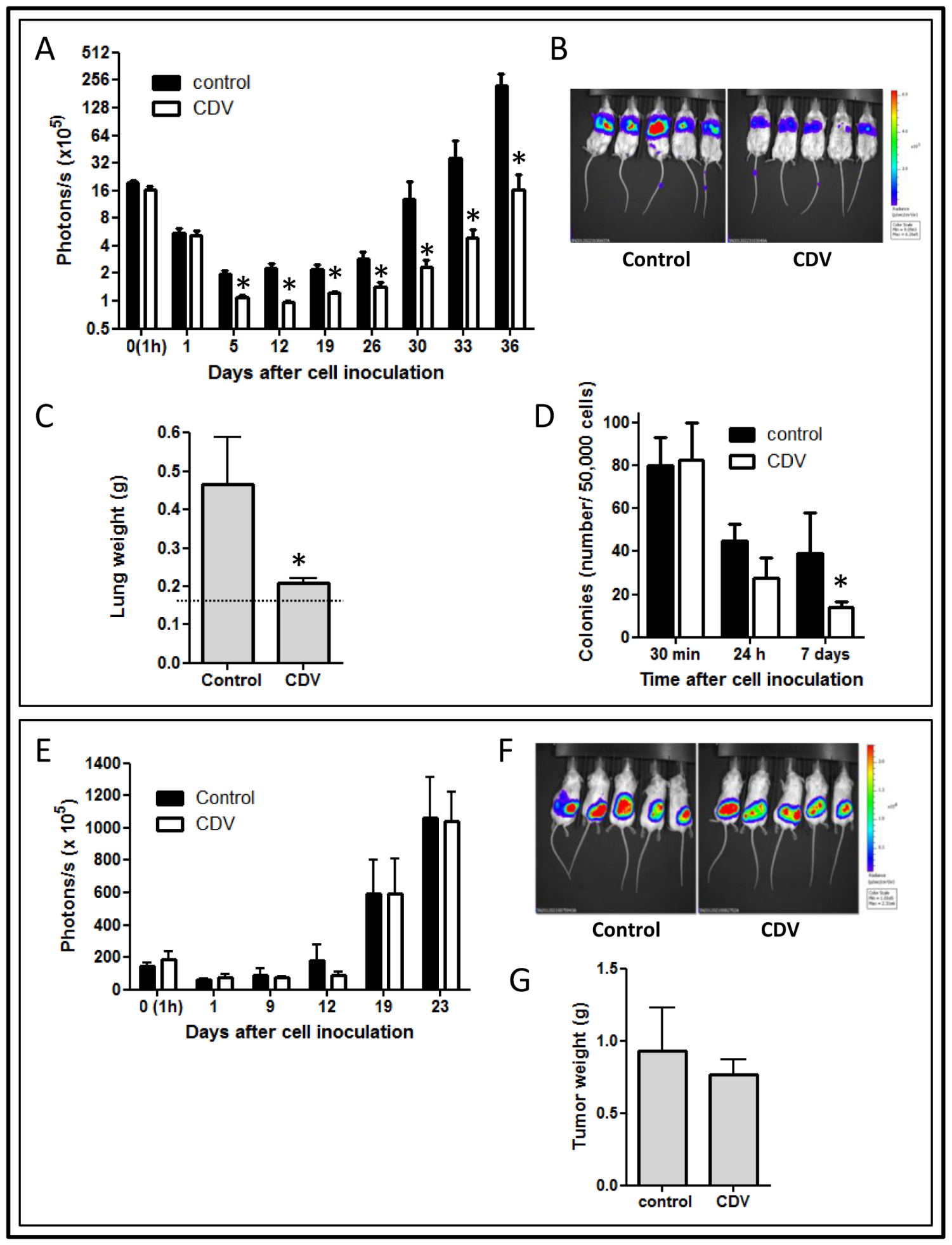

Figure 2: CDV pretreatment of F2T-luc2.9 cells inhibits metastasis but not primary tumor growth. F2T-luc2.9 cells were grown for $24 \mathrm{~h}$ in the absence or presence of $10 \mu \mathrm{g} / \mathrm{ml}$ of CDV. Next, SCID mice were injected i.v. (A-D) or subcutaneously (E-G) with $10^{6}$ control or CDV-treated cells. At regular time intervals, the mice were imaged to assess the growth of luciferase-positive metastases (A) or subcutaneous primary tumors (E). At the end of the experiment, the lungs (C) or subcutaneous tumors $(\mathrm{G})$ were dissected and weighed. Representative pictures of bioluminescence are shown (B, F). Dotted line in C indicates normal lung weight. Three independent experiments yielded comparable data. Values are expressed as mean \pm S.E.M. of one experiment, $n=5$. D, One million cells/200 $\mu 1$ were injected in the tail vein of SCID mice. At indicated time points, lungs were perfused and single-cell suspensions generated. $5 \times 10^{4}$ lungderived cells were plated into a 10-cm tissue culture dish and cultured in F2T-luc2.9-specific medium. Colonies were counted after 14 days. $* \mathrm{p}<0.05$; Student- $t$-test. 
CDV-treated groups (Fig. 2A). Also, CDV did not affect F2T-luc2.9 cell adhesion to the extracellular matrix (ECM) components collagen I, laminin, or fibronectin or to an endothelial cell layer (data not shown). Together, these data indicate that CDV does not influence initial retention/ homing of F2T-luc2.9 cells in the lungs.

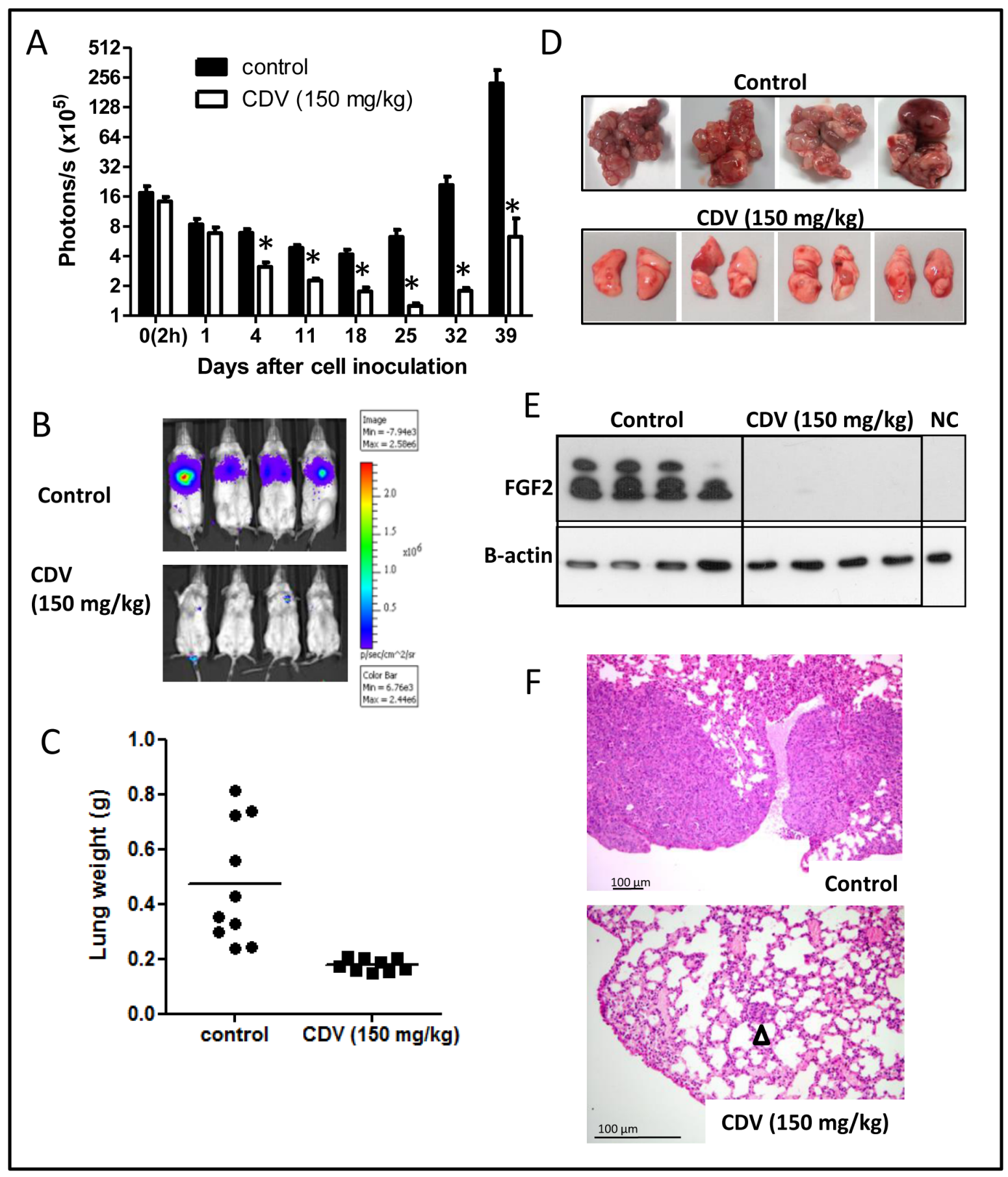

Figure 3: Systemic CDV treatment inhibits the development and growth of F2T-luc2.9 lung metastases. A-F, $10^{6}$ cells $/ 200$ $\mu 1$ were injected i.v. in SCID mice. CDV was administered i.p. at $150 \mathrm{mg} / \mathrm{kg}$, once weekly from $2 \mathrm{~h}$ after cell inoculation till the end of the experiment. At regular time intervals, the mice were imaged to assess the growth of luciferase-positive metastases (A). At the end of the experiment, the lungs were dissected and weighed $(\mathrm{C})$. Representative pictures of bioluminescence in the lungs of control and CDV-treated mice (B), macroscopic pictures (D) and H\&E staining (F) of lungs from control and CDV-treated mice after 39 days are shown. Arrowhead indicates micrometastasis. Two independent experiments yielded comparable data. Results of one experiment are shown. Values are expressed as mean \pm S.E.M. $(n=5),{ }^{*} \mathrm{p}<0.05$, Student- $t$-test. E, Western blot analysis for FGF2 on homogenized and lysed lungs from control and CDV-treated mice and from normal healthy mice (NC, negative control). 
To further investigate the growth potential of lungarrested tumor cells, lungs were harvested at different time points after cell injection. Then, single cell suspensions were generated and allowed to grow for 2 weeks in hygromycin-containing medium selective for F2T-luc2.9 cells (Fig. 2D). As anticipated, no difference was observed in the number of colonies obtained from lungs containing control or CDV-pretreated cells shortly after injection (30 min). However, the colony-forming capacity of CDV-pretreated cells appeared to be reduced when lungs were harvested $24 \mathrm{~h}$ after cell injection; this effect was statistically significant for cells isolated 7 days after cell injection.

On this basis, to assess whether CDV pretreatment affects the intrinsic growth potential of F2T-luc2.9 cells, CDV-pretreated cells $(10 \mu \mathrm{g} / \mathrm{ml}, 24 \mathrm{~h})$ were injected subcutaneously in SCID mice. At variance with the inhibitory effect exerted by CDV pretreatment on the development of F2T-luc2.9 lung metastases, no significant difference in subcutaneous tumor growth could be observed between control and CDV-treated cells (Fig. 2E, F). Accordingly, the weight of the primary subcutaneous tumors harvested 3 weeks after cell injection was not different in the two groups (Fig. 2G). Thus, pretreatment with a low dose of CDV does not affect the intrinsic growth of subcutaneous tumor grafts generated by F2Tluc2.9 cells but hampers single cell survival in vitro and metastatic growth in vivo.

\section{Systemic treatment with CDV impairs lung metastasis of F2T-luc2.9 cells}

Next, we examined whether CDV also protects against lung metastasis when given systemically after tumor cell injection, i.e. in a therapeutic treatment setting. The anti-metastatic activity of CDV was evaluated at 150 $\mathrm{mg} / \mathrm{kg}$ i.p., once weekly, a concentration that suppresses FGF2-T-MAE primary tumor growth without eliciting systemic toxicity [4]. When treatment was started $1 \mathrm{~h}$ after cell inoculation and sustained for 6 weeks, CDV significantly reduced tumor cell survival and outgrowth in the lungs (Fig. 3A), resulting in a markedly reduced metastatic burden and lung weight $(470 \pm 220 \mathrm{mg}$ versus $170 \pm 23 \mathrm{mg}$ for control and CVD-treated mice, respectively) (Fig. 3A-C). Macroscopically, lung tumors were detected in all control animals whereas $83 \%$ of CDV-treated mice appeared tumor-free (Fig. 3D). Also, Western blot analysis performed on lung homogenates from control and 3F2T.luc2-injected animals harvested 5 weeks after cell injection showed a high expression of FGF2 isoforms, an index of the presence of F2T-luc2.9 cell-derived metastases in control lungs. In contrast, low levels of FGF2 were detectable in the lungs from CDVtreated animals (Fig. 3E). Histological analysis confirmed these observations (Fig. 3F) and showed the presence of microscopically detectable lesions in the lungs of CDVtreated mice, indicating that the development of lung metastases was delayed, but not completely prevented, by systemic CDV treatment.

In a second set of experiments, mice were inoculated with a high amount of cells to assess the effect of systemic CDV treatment on animal survival. As shown in Fig. 4A, control mice died $31 \pm 2$ days after tumor cell inoculation. In contrast, $60 \%$ or $29 \%$ of the animals were still alive at day 57 when CDV treatment was initiated $1 \mathrm{~h}$ or 2 days after cell inoculation and continued till the end of the experiment. At this time point, surviving animals showed signs of progressing illness and were euthanized. Thus, CDV protects against lung metastasis when treatment is delayed till 2 days post tumor cell injection, but the inhibitory effect was less pronounced compared with the early treatment group (Fig. 4), suggesting that CDV may act at different steps of the metastatic process after tumor cell homing.

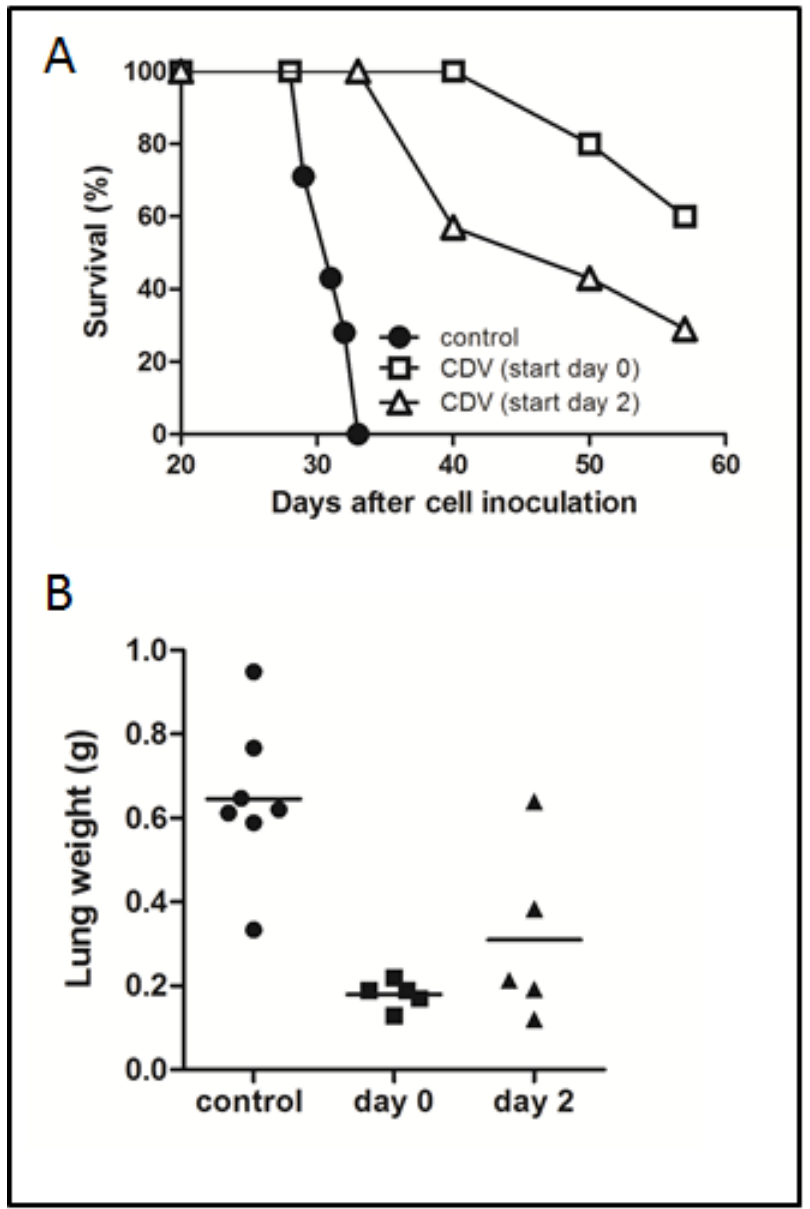

Figure 4: Effect of delayed CDV treatment on metastasis-induced mortality. A, B, 2 x 106 F2T-luc 2.9 cells were injected into the tail vein of SCID mice. CDV treatment $(150 \mathrm{mg} / \mathrm{kg}$ i.p., once weekly) was started either $2 \mathrm{~h}$ or 2 days after cell inoculation and continued for 5 weeks, when the lungs were dissected and weighed (B). Mortality was determined in a parallel group of animals (A). Two independent experiments yielded comparable data. Results of one experiment are shown. 


\section{CDV increases nuclear accumulation of p53}

CDV has been shown to reduce FGF2-T-MAE tumor growth by inducing apoptosis via the upregulation of p53 [4,29]. Thus we reasoned that similar mechanisms might be responsible for the anti-metastatic activity of the drug.

Immunohistochemistry (Fig. 5) was performed on lung metastases from mice that were i.v. injected with untreated F2T-luc2.9 cells (control), CDV-pretreated cells or naïve cells followed by systemic CDV treatment. Five weeks after cell injection, metastases of various sizes were detected throughout control lungs (Fig. 5A). Large $(>1 \mathrm{~mm})$ and medium-size $(200 \mu \mathrm{m}-1 \mathrm{~mm})$ metastases showed high expression of the proliferation marker Ki67, both in the center and at the tumor rim, and were highly vascularized, whereas micrometastases $(<200 \mu \mathrm{m})$ stained

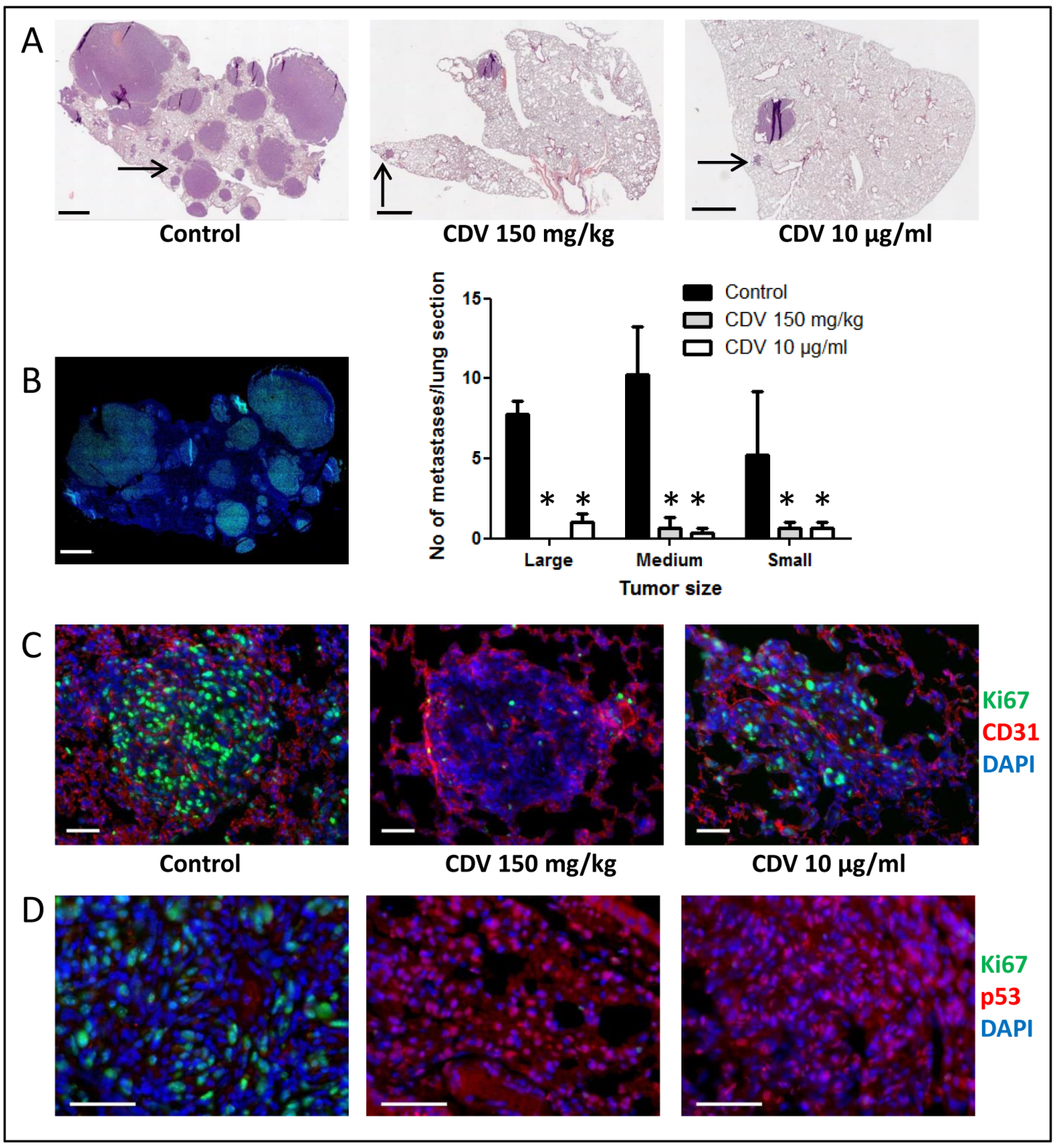

Figure 5: Immunohistochemical analysis of F2T-luc2.9 cell-induced lung metastases. Immunohistochemical analysis was performed on lung metastases from mice collected 5 weeks after i.v. injection of either untreated F2T-luc2.9 cells (control), untreated cells with systemic CDV treatment $(150 \mathrm{mg} / \mathrm{kg}$.week) or CDV-pretreated $(10 \mu \mathrm{g} / \mathrm{ml}, 24 \mathrm{~h})$ cells. A, Total lung sections were stained with $\mathrm{H} \& \mathrm{E}$. Large- $(>1 \mathrm{~mm})$, medium- $(200 \mu \mathrm{m}-1 \mathrm{~mm})$ and small-size $(<200 \mu \mathrm{m})$ metastases were counted. Scale bars: $1 \mathrm{~mm}$. Values are expressed as mean \pm S.E.M. $(\mathrm{n}=5),{ }^{*} \mathrm{p}<0.05$, Student- $t$-test. B, Control metastases are highly proliferative as indicated by prominent Ki67 staining. C, Metastases of comparable size (indicated by the arrows in A) were double immunostained with anti-CD31 (red) and anti-Ki67 (green) antibodies, followed by nuclear counterstaining with DAPI (blue). Scale bars: $50 \mu \mathrm{m}$. D, Ki67 (green)-negative tumors are detected in CDV groups, but not in control lungs, and are characterized by predominant nuclear p53 staining (red). Scale bars: $50 \mu \mathrm{m}$. 
positive for Ki67 (Fig. 5B, C) but appeared to contain fewer blood vessels or were located perivascularly. The tumor suppressor protein p53 was expressed either in the cytoplasm only (Fig. 5D) or in the cytoplasm and nucleus.

In the group of animals injected with CDV-pretreated cells, few vascularized metastases (1-3 per lung section) were evident. Even though most metastases expressed Ki67, Ki67-negative metastases were characterized by $\mathrm{p} 53$ nuclear localization (Fig. 5D). Similarly, metastases in the lungs of CDV-treated mice grafted with naïve F2T-luc2.9 cells were low in number (1-3 per lung section) and smallto medium sized (Fig. 5A). Also in this group, mediumsized lesions did not appear different from control lesions.
However, at variance with the other experimental groups, the lungs of CDV-treated mice were characterized by the presence of avascular micrometastases as well as of small lesions that did not express Ki67 (Fig. 5C). Again, p53 was predominantly located in the nucleus of tumor cells in all Ki67-negative lesions in this group (Fig. 5D).

Thus, in keeping with our previous in vitro observations on FGF2-T-MAE cells [29], CDV may affect the number of F2T-luc2.9 metastases and their growth in vivo by reducing Ki67 expression and increasing nuclear accumulation of $\mathrm{p} 53$.

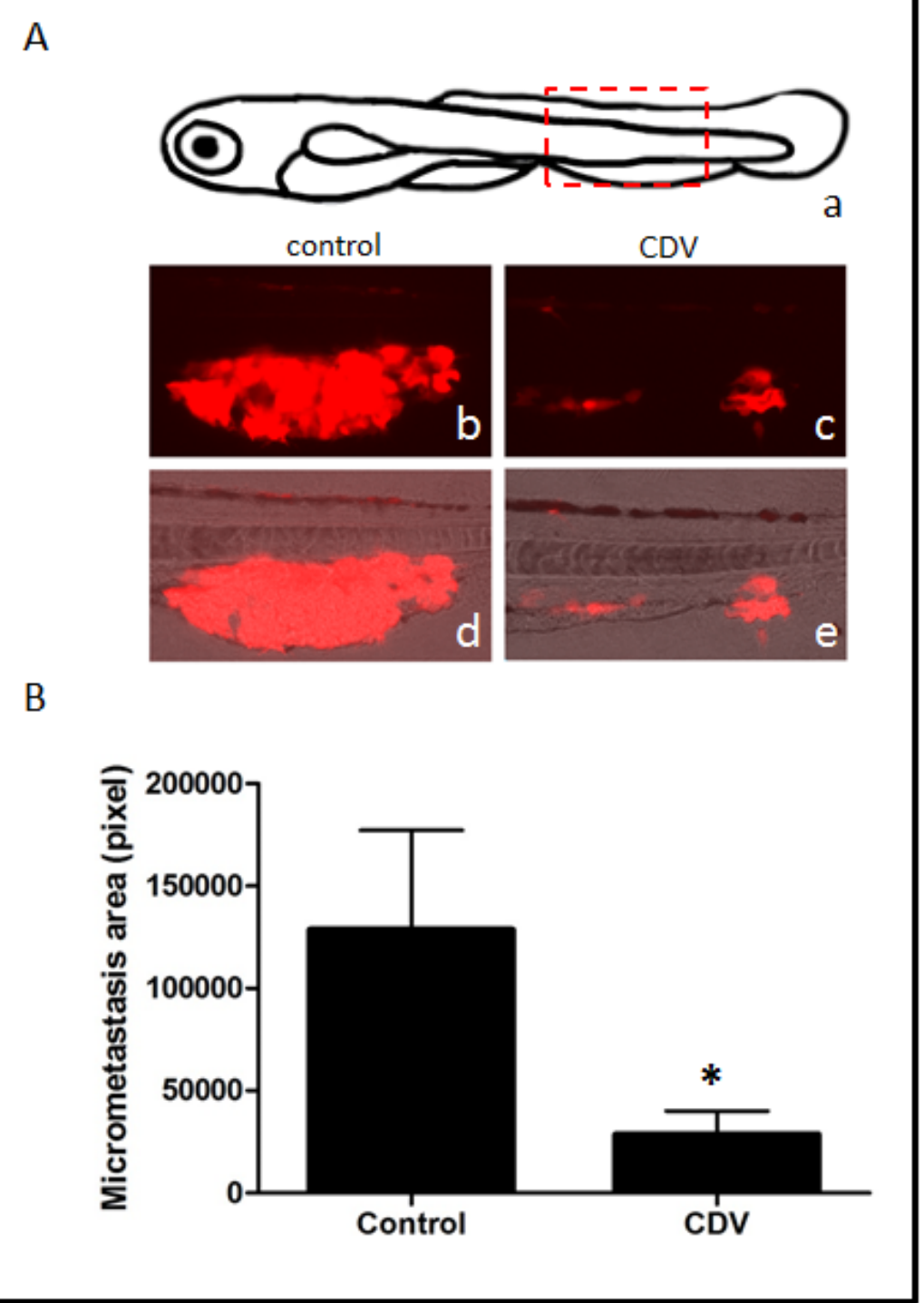

Figure 6: CDV inhibits the metastatic activity of B16-F10 melanoma cells in zebrafish. DsRed-B16-F10 cells were injected in the duct of Cuvier of zebrafish embryos at $48 \mathrm{hpf}$ (80-100 cells/embryo). After $24 \mathrm{~h}$, embryos were transferred to fish water in the absence or in the presence of $100 \mu \mathrm{g} / \mathrm{ml}$ of CDV. Micrometastases were observed under a fluorescence stereo microscope and quantified 5 days after cell injection by computerized image analysis of the embryo tails. A) Schematic drawing of zebrafish embryo at 7 days post-fertilization (a): boxed area highlights the tail region photographed at the end of experimentation. Representative micrometastases (red) in control (b,d) and CDV-treated (c,e) animals. B) DsRed-B16-F10 micrometastases were quantified in the whole tail region of each embryo by computerized image analysis. Data are the mean \pm S.E.M. of $17-20$ embryos per group. ${ }^{*} \mathrm{p}<0.05$; Student- $t$-test. 
CDV inhibits lung metastasis of B16-F10 melanoma cells in zebrafish and mice

FGF2-dependent B16-F10 melanoma cells represent a prototypic model of experimental metastasis following their injection in the bloodstream of mice [36,37] or zebrafish embryos [38]. On this basis, given the prominent role of FGF2 in tumor progression and metastatic activity of these cells [26 and references therein], we investigated whether the anti-metastatic potential of CDV could be extended also to these virus-independent tumor cells.
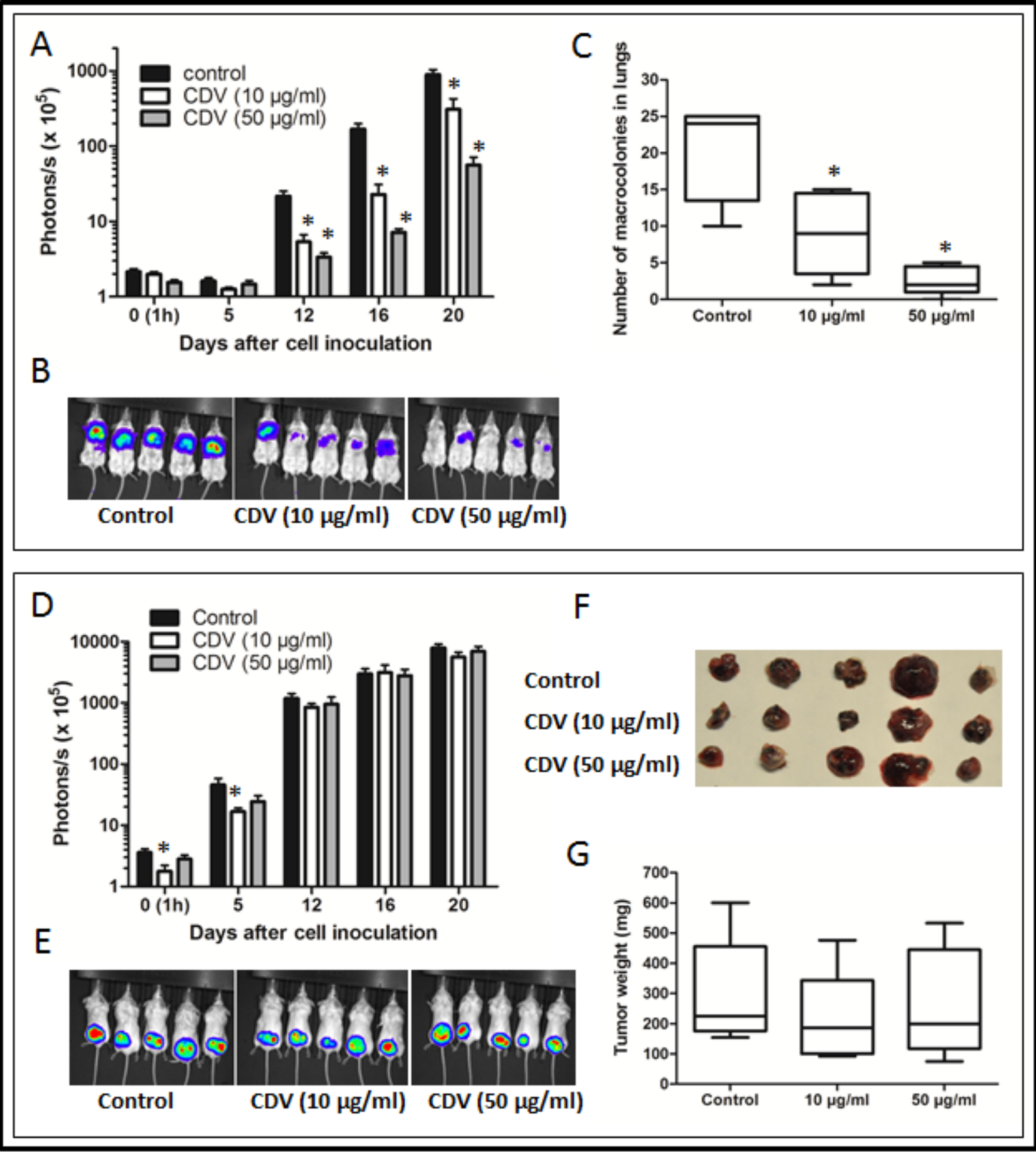

Figure 7: CDV pretreatment inhibits lung metastasis of B16-F10-luc2 melanoma cells. B16-F10-luc2 cells were grown for $24 \mathrm{~h}$ in the absence or presence of 10 or $50 \mu \mathrm{g} / \mathrm{ml}$ of CDV. Next, SCID mice were injected i.v. (A-C) or subcutaneously (D-G) with 30,000 untreated (control) or CDV-treated cells. At regular time intervals, the mice were imaged to assess the growth of luciferase-positive metastases $(A, B)$ or subcutaneous primary tumors $(D, E)$. At the end of the experiment, the lungs $(C)$ or subcutaneous tumors $(F, G)$ were dissected. The number of macrocolonies in the lungs was determined (C) and subcutaneous tumors were weighed (G). Representative pictures of bioluminescence are shown $(\mathrm{B}, \mathrm{E})$. Data are expressed as mean \pm S.E.M of 2 independent experiments, $\mathrm{n}=10{ }^{*} \mathrm{p}<0.05$; Student- $t$-test. 
In a first set of experiments, DsRed-B16-F10 melanoma cells were injected into the blood circulation of zebrafish embryos at $48 \mathrm{hpf}$. After $24 \mathrm{~h}$, embryos were transferred in fish water in the absence or in the presence of $100 \mu \mathrm{g} / \mathrm{ml}$ of CDV and the growth of micrometastases in the tail vascular plexus was followed. As shown in Fig. 6, CDV treatment results in a significant reduction of the size of DsRed-labelled micrometastases when assessed 5 days after cell injection. Of note, CDV did not exert any evident toxic effect on the development of zebrafish embryos when compared to vehicle-treated animals (data not shown).

Next, the effect of CDV on the metastatic activity of B16-F10 melanoma cells was assessed in mice. In accordance with the data obtained with F2T.luc2.9 cells, pretreatment of B16-F10-luc2 cells with CDV abrogated lung metastasis after i.v. injection (Fig. 7A-C) without affecting primary subcutaneous tumor growth (Fig. 7D-G).

\section{DISCUSSION}

Experience with the off-label use of the nucleotide analogue CDV and recent clinical trials indicate that CDV holds great promise as anti-cancer agent for the treatment of high-grade HPV+ carcinomas [16,17]. While CDV preferentially acts on E6/E7 viral oncogene-expressing cells [9], a recent study showed that the compound also inhibits primary glioma growth in human cytomegalovirus (HCMV)-infected as well as in non-infected patients [18], indicating that this compound may exert anti-tumor effects also in virus-independent neoplasms. Indeed, CDV proved effective in the treatment of patients affected by basal cell carcinoma or cutaneous squamous cell carcinoma $[19,20]$. Moreover, CDV reduces the growth of primary murine B16 melanoma tumor grafts [30] and of Kaposi's sarcomalike tumors induced by murine FGF2-overexpressing FGF2-T-MAE cells [4,27,28].

Thus far, the anti-metastatic activity of CDV had been demonstrated only in one experimental model involving HPV+ cells [34]. Here, we provide novel evidence that CDV inhibits experimental lung metastases induced by virus-independent FGF2-T-MAE-derived 3F2T.luc2 tumor cells and B16-F10 melanoma cells, the growth of both cell lines relying on an autocrine activation by FGF2 [4,26].

FGF2 activates FGF receptors (FGFRs) on endothelial cells, resulting in increased tumor vascularization and dissemination of metastatic cells [22]. Accordingly, FGF2 has been shown to play an important role in the pathology of tumors of endothelial cell origin, such as hemangiomas and Kaposi's sarcoma [39-41]. Moreover, levels of circulating FGF2 were suggested to have prognostic value in hematological malignancies, lung cancer, head and neck cancer and melanoma [22,4246]. In other tumor types, such as gastric and esophageal cancer and pediatric glioma, intratumoral levels of FGF2 were shown to correlate with poor clinical outcome [4749]. In melanoma, FGF2 upregulation was found to be accompanied by the expression of FGFRs that triggers an autocrine loop of activation required for melanoma growth and survival $[22,26,50,51]$. Here we show that the injection of DsRed-B16-F10 melanoma cells into the blood circulation of zebrafish embryos results in the growth of micrometastases within 5 days after cell injection. Addition of $100 \mu \mathrm{g} / \mathrm{ml}$ of CDV to the fish water resulted in a significant reduction in the growth of micrometastases, without any evident toxic effect on the development of the embryos. Also, pretreatment of B16F10-luc2 cells with CDV abrogated single cell survival in vitro (data not shown) and lung metastasis after i.v. injection in mice, without affecting primary subcutaneous tumor growth. The anti-metastatic activity of CDV was not limited to B16 melanoma cells. Indeed, our data demonstrate the capacity of the compound to affect also single cell survival of FGF2-dependent 3F2T.luc2 tumor cells and their capacity to induce lung metastases following i.v. injection in immunocompromised animals. These observations pave the way for further studies about the anti-cancer activity of CDV in different FGF2dependent tumors.

Metastasis is a complex multistep process that involves (i) the detachment of tumor cells from the primary tumor, (ii) trans-endothelial cell migration, (iii) transport of the tumor cells through the blood, (iv) tumor cell arrest in a target organ, (v) extravasation into the tissue and (vi) outgrowth of the secondary tumor [reviewed in 32,33]. Thus, compounds that interfere with tumor cell invasion, detachment-free survival, angiogenesis and resistance to apoptosis may inhibit metastasis. In vitro experiments indicate that CDV does not affect F2Tluc 2.9 cell migration or adhesion to the ECM components collagen I, laminin, or fibronectin or to an endothelial cell layer (data not shown). Amine [34] demonstrated that pretreatment of HPV16+ cells with CDV reduces tumor cell metastasis by inhibition of E6 and E7 viral oncogene expression, leading to decreased CXCR4 levels and reduced homing of the cells to the lungs after i.v. injection. However, we found that CXCR4 protein expression at the cell surface was nearly undetectable both in control and CDV-treated F2T-luc2.9 cells, ruling out the possibility that the anti-metastatic action exerted by CDV on these cells may depend on CXCR4 activity. Accordingly, our in vivo observations clearly indicate that CDV does not interfere with F2T-luc2.9 cell homing to the lungs.

CDV reduces the in vitro survival of single F2Tluc2.9 cells both when attached to the substratum or in suspension. This occurred at compound concentrations that did not affect the survival of subconfluent cell cultures. Moreover, pretreatment of F2T-luc2.9 cells with CDV reduced lung metastasis after i.v. injection but did not affect the growth of a subcutaneous primary tumor, pointing to a specific effect of CDV at the single cell level. 
It is well established that the majority of tumor cells die during the first days after arrest in the target organ [52,53]. We found that the massive tumor cell death that occurs in the lungs from day 0 till day 7 after i.v. injection was even more pronounced when F2T-luc2.9 cells were pretreated with CDV and correlated with the reduced colony-forming capacity of these cells when recovered from the lungs 7 days after injection. Together, these data suggest that CDV may affect the survival of single tumor cell colonies or micrometastases in the lung microenvironment [54]. However, despite the pro-apoptotic properties of CDV $[4,5,29]$, we failed to detect apoptotic tumor cells in the lungs of F2T-luc2.9 cell-injected animals 3 and 7 days after grafting (data not shown). This could be due to the paucity of tumor cells present in the lungs at these time points or the fact that apoptotic cells had already been phagocytized and cleared.

The progression from a small avascular nodule to an aggressively growing secondary tumor requires the formation of an intratumoral network of blood vessels $[32,55]$. CDV caused $>90 \%$ reduction in the number of F2T-luc2.9 cell-derived lung metastases with complete inhibition of large-size metastases, suggesting that the compound inhibits both the survival of micrometastases as well as macrometastasis outgrowth. Moreover, whereas control metastases were all well vascularized, avascular micrometastases were detectable in the lungs of CDVtreated mice. Accordingly, CDV was shown to reduce the expression of pro-angiogenic FGF2 in F2T-luc2.9 cells in vitro [29]. In addition, weekly CDV treatment, that results in a nearly continuous exposure to the drug due to its long half-life [56], was able to maintain micrometastases in a dormant state, as shown by the absence of Ki67 expression in (some of) these lesions. Notably, all Ki67-negative lesions showed predominant nuclear staining of p53, whereas p53 was localized solely in the cytoplasm or in the cytoplasm and nucleus in Ki67-positive metastases. Increased nuclear p53 is likely to result in cell cycle arrest [57], as indicated by the absence of Ki67 staining in these lesions. These data suggest that the anti-tumor/antimetastatic activity of CDV might be limited to tumors in which downstream p53 signaling is unaffected.

The p53 pathway has been identified as one of the main targets for CDV also in HPV+ tumors in which increased p53 levels are linked to reduced expression of the viral oncogene E6 $[9,10]$. Further studies will be required to identify the molecular mechanisms linking CDV treatment to increased p53 activity in virusindependent tumors.

Tumor metastases remain the main cause of death in cancer patients, mainly due to late diagnosis and the lack of efficient anti-metastatic drugs. The present study shows for the first time that the FDA-approved antiviral agent CDV inhibits lung metastasis of virus-independent FGF2-driven tumor cells. The concept of using existing drugs for novel applications is very attractive given that treatment can be developed fast and with relatively low costs [58-61]. Developing a new drug can take 10 years or more and costs in excess of 1 billion dollars. Moreover, despite increasing efforts and money being put into research, the number of new drugs approved remains constant. Repurposing old compounds has proven successful in the past and is gaining in popularity [62-65]. In particular, AZT (azidothymidine), a failed anticancer drug, was the first antiviral approved for HIV/AIDS in 1987 [66]. Conversely, the nucleoside analogue Gemzar ${ }^{\circledR}$ (gemcitabine) originally developed as an antiviral agent is now being used to treat pancreatic cancer [67]. Our findings suggest that CDV may have therapeutic potential as an anti-metastatic agent and warrant further studies to select those tumor types that are most likely to benefit from CDV therapy.

\section{MATERIALS AND METHODS}

Cidofovir $\left[\left(\mathrm{CDV}\right.\right.$, Vistide $\left.^{\circledR}\right]$ was obtained from Gilead Sciences (Foster City, CA)

\section{Cell cultures}

FGF2- $T$-MAE cells are murine endothelial cells that express high levels of the $M_{\mathrm{r}} 18,000, M_{\mathrm{r}} 22,000$ and $M_{\mathrm{r}}$ 24,000 molecular weight isoforms of FGF2 [27]. These cells were maintained in Dulbecco's modified minimum essential medium (DMEM, Life Technologies, Inc., Rockville, MD) supplemented with $10 \mathrm{mM}$ Hepes (Life Technologies), 10\% fetal bovine serum (FBS) , $1 \mathrm{mM}$ sodium pyruvate (Life Technologies) and $500 \mu \mathrm{g} / \mathrm{ml}$ geneticin (Invitrogen). F2T-luc2.9 cells were engineered by selecting the brightest clone of FGF2-T-MAE cells transfected with enhanced firefly luciferase (Fluc, Promega, Leiden, The Netherlands) under hygromycin growth conditions (Invitrogen), as described [68]. B16F10-luc2 murine melanoma cells expressing Fluc (Perkin Elmer, Zaventem, Belgium) were maintained in DMEM, supplemented with 10\% FBS.

\section{Cytotoxicity}

Cytotoxicity of CDV was evaluated by the MTS method. Briefly, cells were seeded in 96-well plates at 10,000 cells per $\mathrm{cm}^{2}$. After overnight incubation at $37^{\circ} \mathrm{C}, \mathrm{CDV}(10,20,50$ or $100 \mu \mathrm{g} / \mathrm{ml})$ was added for 24 h. Next, the cells were washed and incubated with fresh medium containing $10 \%$ FBS for another 24,48 or 120 $\mathrm{h}$. To determine the $50 \%$ cytotoxic concentration $\left(\mathrm{CC}_{50}\right)$, the medium was removed and $90 \mu \mathrm{l}$ medium plus $10 \mu \mathrm{l}$ MTS/PMS (Promega) were added to each well. After an incubation period of $2 \mathrm{~h}$ at $37^{\circ} \mathrm{C}$, the optical density of each well was determined at $498 \mathrm{~nm}$ in a microplate reader. 


\section{Anchorage-independent growth}

F2T-luc2.9 cells were grown in culture flasks and pretreated with different concentrations of $\operatorname{CDV}(50,20$ or $10 \mu \mathrm{g} / \mathrm{ml}$ ) for $24 \mathrm{~h}$. Next, the cells were trypsinized and counted. $5.10^{4}$ cells were suspended in $2 \mathrm{ml}$ of medium containing $0.3 \%$ agar and applied onto $2 \mathrm{ml}$ presolidified $0.6 \%$ agar in 6 -well plates in the absence of CDV. Medium was replaced twice weekly. After 2 weeks of incubation, cell colonies were stained with $0.1 \%$ crystal violet in methanol and counted.

\section{Single cell survival}

F2T-luc2.9 cells were treated and seeded as described above. Next, 300 cells were seeded in 6-well plates in the absence of CDV. After 7 days cell colonies were stained and counted.

\section{Animals}

Female severe combined immunodeficient (SCID) mice, weighing about $20 \mathrm{~g}$ were used for all experiments. The animals were bred at the animal facility of the Rega Institute. All studies were done in compliance with the ethical guidelines for animal welfare of the KU Leuven (P028/2011).

\section{Metastasis assays}

Intravenous injection of tumor cells has been used as an experimental model to investigate tumor cell metastasis in mice [35]. Thus, $10^{6}$ (2.10 $0^{6}$ for mortality experiments) F2T-luc2.9 cells were injected into the tail vein of SCID mice. Intraperitoneal (i.p.) treatment with CDV $(150 \mathrm{mg} /$ $\mathrm{kg}$ ) was started $1 \mathrm{~h}$ after cell injection and continued once weekly. The same volume of phosphate-buffered saline (PBS) was given to control mice. Alternatively, F2Tluc 2.9 cells were pretreated with $10 \mu \mathrm{g} / \mathrm{ml}$ of CDV for 24 h. Next, $10^{6}$ cells (untreated or pretreated with CDV) were injected into the tail vein of SCID mice.

B16-F10-luc2 cells were pretreated with 10 or 50 $\mu \mathrm{g} / \mathrm{ml}$ of CDV for $24 \mathrm{~h}$. Next, 30,000 cells were injected into the tail vein of SCID mice.

The mice were imaged at regular time intervals to assess the growth of the luciferase-positive tumor cells. Before imaging, the mice were injected subcutaneously (s.c.) with $200 \mu \mathrm{l}$ of a $15 \mathrm{mg} / \mathrm{ml}$ luciferin solution in PBS. Images were captured by the IVIS spectrum imaging system (Caliper Life Sciences, Hopkinton, MA, USA) and analyzed using the LivingImage software (Caliper Life $\mathrm{Sc}$ ). At the end of the experiment (as indicated in Results), the lungs were weighed and processed for further analysis.

\section{Clonogenic assay for viability of lung-arrested tumor cells}

$10^{6}$ F2T-luc2.9 cells (treated or untreated with CDV) were injected i.v. in SCID mice. At different time points after cell injection (30 min, $24 \mathrm{~h}, 7$ days) lungs were removed, minced and incubated in DMEM containing $0.25 \%$ collagenase type 4 (Sigma-Aldrich) and 300 units DNase I for $1 \mathrm{~h}$ at $37^{\circ} \mathrm{C}$ with agitation. The cells were then passed through a $40 \mu \mathrm{m}$ cell strainer to collect a singlecell suspension. A total of $5 \times 10^{4}$ lung-derived cells were plated into a $10-\mathrm{cm}$ tissue culture dish. Colonies were stained and counted 14 days later.

\section{Primary tumor growth in mice}

SCID mice were inoculated s.c. with $200 \mu$ of serum-free DMEM containing $10^{6}$ F2T.luc2.9 cells (untreated or pretreated with $10 \mu \mathrm{g} / \mathrm{ml} \mathrm{CDV}$ ) or 30,000 B16-F10-luc2 cells (untreated or pretreated with 10 or $50 \mu \mathrm{g} / \mathrm{ml} \mathrm{CDV}$ ). The mice were imaged at regular time intervals to assess the growth of the luciferase-positive tumor cells. At the end of the experiment, the tumors were excised and weighed.

\section{Histological and immunohistochemical analyses}

At indicated time points, mice were euthanized by i.p. injection of pentobarbital. Lungs were washed with PBS via intracardiac perfusion and fixed intratracheally with $4 \%$ paraformaldehyde. Dissected lungs were fixed overnight at room temperature and stored in PBS until paraffin sectioning. Paraffin-embedded sections were deparaffinized in xylene and rehydrated through a decreasing concentration of alcohol. Four micron sections were prepared and subsequently stained with hematoxylin and eosin (H\&E). The presence of metastatic nodules in the lungs was evaluated microscopically.

For immunohistochemistry, heat-induced antigen retrieval was done in citrate buffer ( $\mathrm{pH} \mathrm{6)}$ using a microwave. Sections were permeabilized for $30 \mathrm{~min}$ at room temperature with $0.25 \%$ Triton X-100 (Sigma) in PBS containing $0.5 \%$ BSA, washed with PBS and blocked with $5 \%$ goat serum (Sigma) in PBS containing $0.5 \%$ BSA for $30 \mathrm{~min}$ at room temperature. After washing, sections were incubated overnight at $4^{\circ} \mathrm{C}$ with a rabbit anti-CD31 (5 $\mu \mathrm{g} / \mathrm{ml}$, abcam), rat anti-Ki67 (1 $\mu \mathrm{g} / \mathrm{ml}$, eBioscience) or mouse anti-p53 $(4 \mu \mathrm{g} / \mathrm{ml}$, Novus Biologicals, Cambridge, UK). After washing with PBS containing 0.01\% Tween20, sections were incubated for $3 \mathrm{~h}$ at room temperature with an Alexa Fluor 568 goat anti-rabbit antibody (Molecular probes), Alexa Fluor 647 goat anti-mouse antibody (Molecular probes) and Dylight 650 conjugated goat antirat antibody (Thermofisher). Sections were washed with 
PBS containing $0.01 \%$ Tween 20 and incubated with $2 \mu \mathrm{g} /$ $\mathrm{ml}$ Hoechst (Sigma) for $30 \mathrm{~min}$ at room temperature. After washing, sections were mounted with $1 \%$ n-propyl gallate and sealed with nail polish. Fluorescent microscopic analysis was done with an Axiovert $200 \mathrm{M}$ inverted microscope (Zeiss, Göttingen, Germany), using a PlanApochromat 20x/0.8 objective. Pictures were taken with an AxioCam MRm camera and processed with AxioVision Release 4.6 software (Zeiss).

\section{Western blot analysis of lung samples}

Homogenized lungs were lysed on ice in $500 \mu \mathrm{l}$ lysis buffer [20 mM Tris- $\mathrm{HCl}$ (pH 7.4), $137 \mathrm{mM} \mathrm{NaCl}$, 2 mM EDTA (pH 7.4), 1\% Triton X-100, 10\% glycerol, $1 \mathrm{mM}$ sodium vanadate, $2 \mathrm{mM}$ sodium pyrophosphate, $1 \mathrm{mM}$ phenylmethylsulfonyl fluoride, $25 \mathrm{mM}$ glycerophosphate and $10 \mu \mathrm{g} / \mathrm{ml}$ leupeptin]. Lysates were cleared by centrifugation and the protein concentration was determined. SDS-PAGE gel electrophoresis of the cell lysates were performed as described [29]. After electrophoresis, proteins were transferred to pretreated Hybond-P polyvinylidene difluoride (PVDF) membranes (Amersham Biosciences). The membranes were incubated for $1 \mathrm{~h}$ at room temperature in blocking buffer $(5 \%$ non-fat dry milk in PBS containing $0.1 \%$ Tween) and subsequently for $12 \mathrm{~h}$ at $4{ }^{\circ} \mathrm{C}$ in blocking buffer with primary antibodies raised against $\beta$-actin (1/5000, Sigma) or FGF2 (clone FB$8,1 / 5000$, Sigma). After washing, the membranes were incubated with the corresponding horseradish peroxidaseconjugated secondary antibody (anti-mouse: 1/2000 or anti-rabbit: 1/4000, Dako) in blocking buffer for $25 \mathrm{~min}$ at room temperature. Next, the membranes were washed extensively. Immunoreactive proteins were detected by chemiluminescence (ECLplus, Bio-Rad). Samples were collected from 3 independent experiments.

\section{Metastasis assay in zebrafish embryos}

The wild-type AB zebrafish line was maintained at the Zebrafish Facilities of the University of Brescia as described [69]. B16-F10 melanoma cells stably transfected with DsRed fluorescent protein (DsRed-B16-F10 cells) were injected in the blood circulation in the ventral region of the duct of Cuvier of zebrafish embryos (80-100 cells/embryo) at $48 \mathrm{~h}$ post-fertilization (hpf). After $24 \mathrm{~h}$, embryos were transferred in fish water in the absence or in the presence of $100 \mu \mathrm{g} / \mathrm{ml}$ of CDV and the growth of tail micrometastases was followed under a fluorescence stereo microscope and quantified 5 days after cell injection by computerized image analysis of the embryo tails as described [38]. After cell injection, embryos were maintained at $33^{\circ} \mathrm{C}$ throughout the whole experimental period.

\section{Statistical analyses}

Two-tailed Student's $t$ test was used to determine the statistical significance of the data; $p$ values $<0.05$ were considered significant.

\section{ACKNOWLEDGMENTS}

This work was supported in part by grants from the KU Leuven (GOA no. 15/019/TBA) to S.L. and Ministero dell'Istruzione, Università e Ricerca (FIRB project RBAP11H2R9 2011) and Associazione Italiana per la Ricerca sul Cancro (AIRC grant $n^{\circ} 14395$ ) to M.P. We wish to thank Eef Meyen and Wilfried Versin for excellent technical assistance.

\section{REFERENCES}

1. De Clercq E, Holý A, Rosenberg I, Sakuma T, Balzarini J, Maudgal PC. A novel selective broad-spectrum anti-DNA virus agent. Nature. 1986; 323: 464-467.

2. De Clercq E, Holý A. Acyclic nucleoside phosphonates: a key class of antiviral drugs. Nat Rev Drug Discov. 2005; 4: 928-940.

3. Neyts J, Sadler R, De Clercq E, Raab-Traub N, Pagano JS. The antiviral agent cidofovir[(S)-1-(3-hydroxy-2phosphonyl-methoxypropyl)cytosine] has pronounced activity against nasopharyngeal carcinoma grown in nude mice. Cancer Res. 1998; 58: 384-388.

4. Liekens S, Neyts J, De Clercq E, Verbeken E, Ribatti D, Presta M. Inhibition of fibroblast growth factor-2-induced vascular tumor formation by the acyclic nucleoside phosphonate cidofovir. Cancer Res. 2001a; 61: 5057-5064.

5. Liekens S, Verbeken E, De Clercq E, Neyts J. Potent inhibition of hemangiosarcoma development in mice by cidofovir. Int J Cancer. 2001b; 92: 161-167.

6. Murono S, Raab-Traub N, Pagano JS. Prevention and inhibition of nasopharyngeal carcinoma growth by antiviral phosphonated nucleoside analogs. Cancer Res. 2001; 61: 7875-7877.

7. De Schutter T, Andrei G, Topalis D, Duraffour S, Mitera $\mathrm{T}$, van den Oord J, Matthys P, Snoeck R. Reduced tumorigenicity and pathogenicity of cervical carcinoma $\mathrm{SiHa}$ cells selected for resistance to cidofovir. Mol Cancer. 2013; 12: 158-173.

8. Yang Y, Zhao X, Chen W, Gao Z, Liu A, Guo J, Yan Z, Dou Y, Wang H, Li Y. Effects of cidofovir on human papillomavirus-positive cervical cancer cells xenografts in nude mice. Oncol Res. 2010; 18: 519-527.

9. Abdulkarim B, Sabri S, Deutsch E, Chagraoui H, Maggiorella L, Thierry J, Eschwege F, Vainchenker W, Chouaib S, Bourhis J. Antiviral agent Cidofovir restores p53 function and enhances the radiosensitivity in HPVassociated cancers. Oncogene. 2002; 21: 2334-2346. 
10. Amine A, Vozenin-Brotons MC, Abdulkarim B, Violot D, Aubel C, Bourhis J. Cidofovir administered with radiation displays an antiangiogenic effect mediated by E6 inhibition and subsequent TP53-dependent VEGF repression in HPV18+ cell lines. Radiat Res. 2006; 166: 600-610.

11. Sirianni N, Wang J, Ferris RL. Antiviral activity of Cidofovir on a naturally human papillomavirus-16 infected squamous cell carcinoma of the head and neck(SCCHN) cell line improves radiation sensitivity. Oral Oncol. 2005; 41: 423-428.

12. Tristram A, Fiander A. Clinical responses to Cidofovir applied topically to women with high grade vulval intraepithelial neoplasia. Gynecol Oncol. 2005; 99: 652655.

13. Yoshizaki T, Wakisaka N, Kondo S, Murono S, Shimizu Y, Nakashima M, Tsuji A,Furukawa. Treatment of locally recurrent Epstein-Barr virus-associated nasopharyngeal carcinoma using the anti-viral agent cidofovir. J Med Virol. 2008; 80: 879-882.

14. Stier EA, Goldstone SE, Einstein MH, Jay N, Berry JM, Wilkin T, Lee JY, Darragh TM, Da Costa M, Panther L, Aboulafia D, Palefsky JM. Safety and efficacy of topical cidofovir to treat high-grade perianal and vulvar intraepithelial neoplasia in HIV-positive men and women. AIDS. 2013; 27: 545-551.

15. Tristram A, Hurt CN, Madden T, Powell N, Man S, Hibbitts S, Dutton P, Jones S, Nordin AJ, Naik R, Fiander A, Griffiths G. Activity, safety, and feasibility of cidofovir and imiquimod for treatment of vulval intraepithelial neoplasia (RT(3)VIN): a multicentre, open-label, randomised, phase 2 trial. Lancet Oncol. 2014 [Epub ahead of print] doi: 10.1016/S1470-2045(14)70456-5.

16. Clamp PJ, Saunders MW. Systematic review of intralesional cidofovir dosing regimens in the treatment of recurrent respiratory papillomatosis. Int J Pediatr Otorhinolaryngol. 2013; 77: 323-328.

17. Van Pachterbeke C, Bucella D, Rozenberg S, Manigart Y, Gilles C, Larsimont D, Vanden Houte K, Reynders M, Snoeck R, Bossens M. Topical treatment of CIN 2+ by cidofovir: results of a phase II, double-blind, prospective, placebo-controlled study. Gynecol Oncol. 2009; 115: 69-74.

18. Hadaczek P, Ozawa T, Soroceanu L, Yoshida Y, Matlaf L, Singer E, Fiallos E, James CD, Cobbs CS. Cidofovir: a novel antitumor agent for glioblastoma. Clin Cancer Res. 2013; 19: 6473-6483.

19. Calista D. Topical $1 \%$ cidofovir for the treatment of basal cell carcinoma. Eur J Dermatol. 2002a; 12: 562-564.

20. Calista D, Riccioni L, Coccia L. Successful treatment of squamous cell carcinoma of the lower eyelid with intralesional cidofovir. Br J Ophthalmol. 2002b; 86: 932933.

21. Presta M, Moscatelli D, Joseph-Silverstein J, Rifkin DB. Purification from a human hepatoma cell line of a basic fibroblast growth factor-like molecule that stimulates capillary endothelial cell plasminogen activator production, DNA synthesis, and migration. Mol Cell Biol. 1986; 6: 4060-4066.

22. Presta M, Dell'Era P, Mitola S, Moroni E, Ronca R, Rusnati M. Fibroblast growth factor/fibroblast growth factor receptor system in angiogenesis. Cytokine Growth Factor Rev. 2005; 16: 159-178.

23. Nissen LJ, Cao R, Hedlund EM, Wang Z, Zhao X, Wetterskog D, Funa K,Bråkenhielm E, Cao Y. Angiogenic factors FGF2 and PDGF-BB synergistically promote murine tumor neovascularization and metastasis. J Clin Invest. 2007; 117: 2766-2777.

24. Thomas-Mudge RJ, Okada-Ban M, Vandenbroucke F, Vincent-Salomon A, Girault JM, Thiery JP, Jouanneau J. Nuclear FGF-2 facilitates cell survival in vitro and during establishment of metastases. Oncogene. 2004; 23: 47714779.

25. Bono F, De Smet F, Herbert C, De Bock K, Georgiadou M, Fons P, Tjwa M, Alcouffe C, Ny A, Bianciotto M, Jonckx B, Murakami M, Lanahan AA, et al. Inhibition of tumor angiogenesis and growth by a small-molecule multi-FGF receptor blocker with allosteric properties. Cancer Cell. 2013; 23: 477-488.

26. Ronca R, Alessi P, Coltrini D, Di Salle E, Giacomini A, Leali D, Corsini M, Belleri M, Tobia C, Garlanda C, Bonomi E, Tardanico R, Vermi W et al. Long pentraxin-3 as an epithelial-stromal fibroblast growth factor-targeting inhibitor in prostate cancer. J Pathol. 2013; 230: 228-238.

27. Gualandris A, Rusnati M, Belleri M, Nelli EE, Bastaki M, Molinari-Tosatti MP, Bonardi F, Parolini S, Albini A, Morbidelli L, Ziche M, Corallini A, Possati L et al. Basic fibroblast growth factor overexpression in endothelial cells: an autocrine mechanism for angiogenesis and angioproliferative diseases. Cell Growth Differ. 1996; 7 : 147-160.

28. Sola F, Gualandris A, Belleri M, Giuliani R, Coltrini D, Bastaki M, Tosatti MP, Bonardi F, Vecchi A, Fioretti F, Ciomei M, Grandi M, Mantovani A et al. Endothelial cells overexpressing basic fibroblast growth factor (FGF2) induce vascular tumors in immunodeficient mice. Angiogenesis. 1997; 1: 102-106.

29. Liekens S, Gijsbers S, Vanstreels E, Daelemans D, De Clercq E, Hatse S. The nucleotide analog cidofovir suppresses basic fibroblast growth factor (FGF2) expression and signaling and induces apoptosis in FGF2overexpressing endothelial cells. Mol Pharmacol. 2007; 71: 695-703.

30. Redondo P, Idoate M, Galofré JC, Solano T. Cidofovir inhibits growth of B16 melanoma cells in vivo. Br J Dermatol. 2000; 143: 741-748.

31. Calista D. Regression of a cutaneous melanoma metastasis after intralesional cidofovir. Melanoma Res. 2003; 13: 205206.

32. Steeg PS, Theodorescu D. Metastasis: a therapeutic target 
for cancer. Nat Clin Pract Oncol. 2008; 5: 206-219.

33. Sethi N, Kang Y. Unravelling the complexity of metastasis - molecular understanding and targeted therapies. Nat Rev Cancer. 2011; 11: 735-748.

34. Amine A, Rivera S, Opolon P, Dekkal M, Biard DS, Bouamar H, Louache F, McKay MJ, Bourhis J, Deutsch E, Vozenin-Brotons MC. Novel anti-metastatic action of cidofovir mediated by inhibition of E6/E7, CXCR4 and Rho/ROCK signaling in HPV tumor cells. PLoS One. 2009; 4: e5018.

35. Rashid OM, Nagahashi M, Ramachandran S, Dumur CI, Schaum JC, Yamada A, Aoyagi T, Milstien S, Spiegel S, Takabe K. Is tail vein injection a relevant breast cancer lung metastasis model? J Thorac Dis. 2013; 5: 385-392.

36. Fidler IJ, Nicolson GL. Organ selectivity for implantation survival and growth of B16 melanoma variant tumor lines. J Natl Cancer Inst. 1976; 57: 1199-1202.

37. Baniyash M, Netanel T, Witz IP. Differences in cell density associated with differences in lung-colonizing ability of B16 melanoma cells. Cancer Res. 1981; 41: 433-437.

38. Tobia C, Gariano G, De Sena G, Presta M. Zebrafish embryo as a tool to study tumor/endothelial cell cross-talk. Biochim Biophys Acta. 2013; 1832: 1371-1377.

39. Takahashi K, Mulliken JB, Kozakewich HP, Rogers RA, Folkman J, Ezekowitz RA. Cellular markers that distinguish the phases of hemangioma during infancy and childhood. J Clin Invest. 1994; 93: 2357-2364.

40. Ensoli B, Markham P, Kao V, Barillari G, Fiorelli V, Gendelman R, Raffeld M, Zon G, Gallo RC. Block of AIDS-Kaposi's sarcoma (KS) cell growth, angiogenesis, and lesion formation in nude mice by antisense oligonucleotide targeting basic fibroblast growth factor. A novel strategy for the therapy of KS. J Clin Invest. 1994; 94: 1736-1746.

41. Ensoli B, Gendelman R, Markham P, Fiorelli V, Colombini S, Raffeld M, Cafaro A, Chang HK, Brady JN, Gallo RC. Synergy between basic fibroblast growth factor and HIV-1 Tat protein in induction of Kaposi's sarcoma. Nature. 1994; 371: 674-680.

42. Perez-Atayde AR, Sallan SE, Tedrow U, Connors S, Allred E, Folkman J. Spectrum of tumor angiogenesis in the bone marrow of children with acute lymphoblastic leukemia. Am J Pathol. 1997; 150: 815-821.

43. Salven P, Teerenhovi L, Joensuu H. A high pretreatment serum basic fibroblast growth factor concentration is an independent predictor of poor prognosis in non-Hodgkin's lymphoma. Blood. 1999; 94: 3334-3339.

44. Dietz A, Rudat V, Conradt C, Weidauer H, Ho A, Moehler T. Prognostic relevance of serum levels of the angiogenic peptide bFGF in advanced carcinoma of the head and neck treated by primary radiochemotherapy. Head Neck. 2000; 22: 666-673.

45. Joensuu H, Anttonen A, Eriksson M, Mäkitaro R, Alfthan H, Kinnula V, Leppä S. Soluble syndecan-1 and serum basic fibroblast growth factor are new prognostic factors in lung cancer. Cancer Res. 2002; 62: 5210-5217.

46. Kurschat P, Eming S, Nashan D, Krieg T, Mauch C. Early increase in serum levels of the angiogenesisinhibitor endostatin and of basic fibroblast growth factor in melanoma patients during disease progression. $\mathrm{Br} \mathrm{J}$ Dermatol. 2007; 156: 653-658.

47. Bredel M, Pollack IF, Campbell JW, Hamilton RL. Basic fibroblast growth factor expression as a predictor of prognosis in pediatric high-grade gliomas. Clin Cancer Res. 1997; 3: 2157-2164.

48. Barclay C, Li AW, Geldenhuys L, Baguma-Nibasheka M, Porter GA, Veugelers PJ, Murphy PR, Casson AG. Basic fibroblast growth factor (FGF-2) overexpression is a risk factor for esophageal cancer recurrence and reduced survival, which is ameliorated by coexpression of the FGF2 antisense gene. Clin Cancer Res. 2005; 11: 7683-7691.

49. Zhang W, Chu YQ, Ye ZY, Zhao ZS, Tao HQ. Expression of hepatocyte growth factor and basic fibroblast growth factor as prognostic indicators in gastric cancer. Anat Rec. (Hoboken) 2009; 292: 1114-1121.

50. Halaban R, Kwon BS, Ghosh S, Delli Bovi P, Baird A. $\mathrm{bFGF}$ as an autocrine growth factor for human melanomas. Oncogene Res. 1988; 3: 177-186.

51. Jeffers M, LaRochelle WJ, Lichenstein HS. Fibroblast growth factors in cancer:therapeutic possibilities. Expert Opin Ther Targets. 2002; 6: 469-482.

52. Luzzi KJ, MacDonald IC, Schmidt EE, Kerkvliet N, Morris VL, Chambers AF, Groom AC. Multistep nature of metastatic inefficiency: dormancy of solitary cells after successful extravasation and limited survival of early micrometastases. Am J Pathol. 1998; 153: 865-873.

53. Al-Mehdi AB, Tozawa K, Fisher AB, Shientag L, Lee A, Muschel RJ. Intravascular origin of metastasis from the proliferation of endothelium-attached tumor cells: a new model for metastasis. Nat Med. 2000; 6: 100-102.

54. Mehlen P, Puisieux A. Metastasis: a question of life or death. Nat Rev Cancer. 2006; 6: 449-458.

55. Folkman J. Role of angiogenesis in tumor growth and metastasis. Semin Oncol. 2002; 29: 15-18.

56. Ho HT, Woods KL, Bronson JJ, De Boeck H, Martin JC, Hitchcock MJ. Intracellular metabolism of the antiherpes agent(S)-1-[3-hydroxy-2-(phosphonylmethoxy) propyl] cytosine. Mol Pharmacol. 1992; 41: 197-202.

57. Brown CJ, Lain S, Verma CS, Fersht AR, Lane DP. Awakening guardian angels:drugging the p53 pathway. Nat Rev Cancer. 2009; 9: 862-873.

58. Blagosklonny MV. A new science-business paradigm in anticancer drug development. Trends Biotechnol. 2003; 21: 103-106.

59. Aronson JK. Old drugs--new uses. Br J Clin Pharmacol. 2007; 64: 563-565.

60. Chong CR, Sullivan DJ Jr. New uses for old drugs. Nature. 2007; 448: 645-646.

61. Blagosklonny MV. Common drugs and treatments for 
cancer and age-related diseases: revitalizing answers to NCI's provocative questions. Oncotarget. 2012; 3: 17111724.

62. Vainio P, Lehtinen L, Mirtti T, Hilvo M, Seppänen-Laakso T, Virtanen J, Sankila A, Nordling S, Lundin J, Rannikko A, Oreši M, Kallioniemi O, Iljin K. Phospholipase PLA2G7, associated with aggressive prostate cancer, promotes prostate cancer cell migration and invasion and is inhibited by statins. Oncotarget. 2011; 2: 1176-1190.

63. Qi C, Zhou Q, Li B, Yang Y, Cao L, Ye Y, Li J, Ding Y, Wang H, Wang J, He X, Zhang Q, Lan T et al. Glipizide, an antidiabetic drug, suppresses tumor growth and metastasis by inhibiting angiogenesis. Oncotarget. 2014; 5: 9966-9979.

64. Liu N, Li X, Huang H, Zhao C, Liao S, Yang C, Liu S, Song W, Lu X, Lan X, Chen X, Yi S, Xu L et al. Clinically used antirheumatic agent auranofin is a proteasomal deubiquitinase inhibitor and inhibits tumor growth. Oncotarget. 2014; 5: 5453-5471.

65. Gritti M, Würth R, Angelini M, Barbieri F, Peretti M, Pizzi E, Pattarozzi A, Carra E, Sirito R, Daga A, Curmi PM, Mazzanti M, Florio T. Metformin repositioning as antitumoral agent: selective antiproliferative effects in human glioblastoma stem cells, via inhibition of CLIC1mediated ion current. Oncotarget. 2014; 5: 11252-11268.

66. Broder S. The development of antiretroviral therapy and its impact on the HIV-1/AIDS pandemic. Antiviral Res. 2010; 85: 1-18.

67. Oettle H. Progress in the knowledge and treatment of advanced pancreatic cancer: from benchside to bedside. Cancer Treat Rev. 2014; 40: 1039-47.

68. Liekens S, Bronckaers A, Belleri M, Bugatti A, Sienaert R, Ribatti D, Nico B, Gigante A, Casanova E, Opdenakker G, Pérez-Pérez MJ, Balzarini J, Presta M. The thymidine phosphorylase inhibitor 5'-O-tritylinosine (KIN59) is an antiangiogenic multitarget fibroblast growth factor-2 antagonist. Mol Cancer Ther. 2012; 11: 817-829.

69. Westerfield M. The Zebrafish book. Eugene, OR: University of Oregon Press. 1995. 